\title{
Rapid correction by 1- $\alpha$-hydroxycholecalciferol of hemichorea in surgical hypoparathyroidism
}

\author{
IBRAHIM SALTI, AMIN FARIS, NIZAR TANNIR, KHALIL KHOURI \\ From the Divisions of Endocrinology and Neurology, Department of Internal Medicine, Faculty of \\ Medicine, American University of Beirut, Beirut, Lebanon
}

SUMMARY A 45-year-old woman with long standing surgical hypoparathyroidism presented with right hemichorea of three months' duration. She had profound hypocalcaemia and hyperphosphataemia and extensive cerebral, cerebellar and basal ganglia calcification. Correction of the chemical abnormalities with $1 \alpha$-hydroxycholecalciferol, calcium supplements and aluminium hydroxide resulted within 10 weeks in complete disappearance of the abnormal movements.

Parkinsonism and other extrapyramidal abnormalities such as chorea are neurological complications of long standing hypoparathyroidism. ${ }^{1-4}$ Like basal ganglia calcification, their incidence is less frequent in surgical than in idiopathic hypoparathyroidism or pseudohypoparathyroidism. ${ }^{4-6}$ This report describes a patient with surgical hypoparathyroidism who developed right hemichorea 18 years after a subtotal thyroidectomy. Extensive calcification was demonstrated in the basal ganglia, cerebellum and cerebrum by computer tomography, but not by routine skull radiography.

\section{Case report}

A 45-year-old woman underwent 18 years earlier a subtotal thyroidectomy for a nodular goitre. Shortly after the operation, she experienced carpal spasm and tetany necessitating intravenous and later oral calcium gluconate therapy. Thereafter she was advised to continue oral calcium supplements which she took erratically over the following 18 years. In general she took the treatment for a few days whenever she experienced paraesthesias or carpal spasm. No serum calcium determinations were done. She was also placed on L-thyroxin $(0.2 \mathrm{mg}$ per day) which she took regularly after the operation. Three months prior to presentation to this hospital, she experienced jerky involuntary non-rythmic movements of the right arm, hand and leg. The condition

Address for reprint requests: Dr IS Salti, Department of Internal Medicine, American University of Beirut Medical Center, Beirut, Lebanon.

Received 29 July 1981

Accepted 29 August 1981 became progressively worse over the ensuing three months. No similar movements were noted on the left side or in the neck or face. She denied any loss of consciousness, headache, visual disturbances or muscular weakness. There was no similar case in the family. She denied intake of phenothiazines and there was no history suggestive of rheumatic fever or liver dysfunction.

Examination revealed an alert communicative well oriented woman with normal mood and facies. Motor power, sensory examination and cranial nerves were normal. There were early bilateral cataracts; vision was normal and the optic fundi revealed no papilloedema. Speech and gait were normal. The thyroid was not palpable in the neck and, clinically, she was in a euthyroid state. Trousseau and Chvostek signs were positive bilaterally. During the examination, the patient was continuously having right-sided jerky choreic involuntary movements occurring at the rate of six to seven per minute. There was no hepatomegaly or splenomegaly.

The following laboratory examinations were normal: haemoglobin, haematosrit, leukocyte count and differential, urine analysis, serum glucose, creatinine, urea nitrogen, total protein, albumin, globulin, magnesium, sodium, potassium, chloride, bicarbonate, bilirubin and alkaline phosphatase. Serum VDRL was non-reactive. Serum calcium was $1.2-1.4 \mathrm{mmol} / 1$ (normal range: $2 \cdot 1-2 \cdot 6)$ and serum inorganic phosphorus $1 \cdot 9-2 \cdot 1 \mathrm{mmol} / \mathrm{l}$ (normal range: 0.9-1.6). Electroencephalography, skull and chest radiography and a pertechnetate brain scan were all normal. In particular there was no calcification seen in the routine skull films. However, computed tomography (CT) showed extensive bilateral calcification in the basal ganglia, cerebellum and cerebral cortex (fig). An electrocardiogram showed a prolonged Q-T interval. Serum thyroxin was $124 \mathrm{nmol} / \mathrm{l}$ (normal range: 64-154) and serum thyrotropin was $0.5 \mu \mathrm{U} / \mathrm{ml}$ (normal range: $0-7)$. 


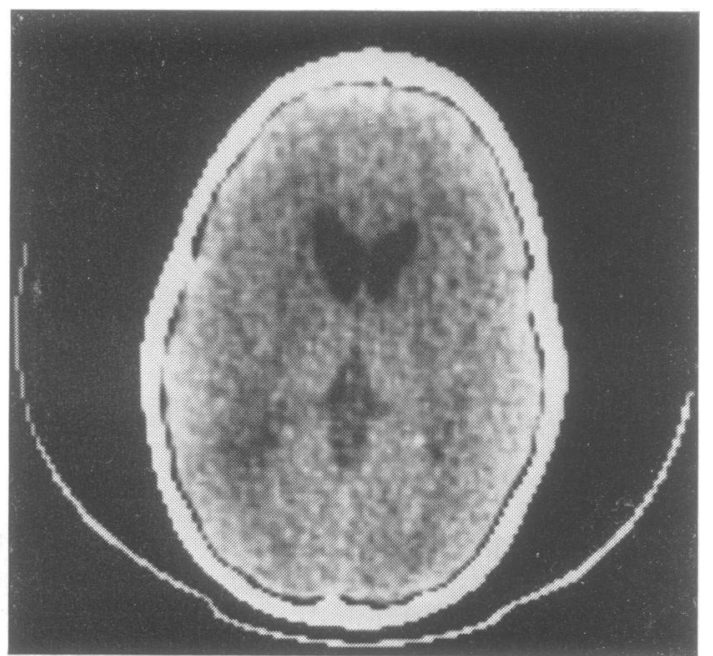

Figure Computed tomography showing basal ganglia, cerebral and cerebellar calcification.

Treatment with L-thyroxin, $0.2 \mathrm{mg}$ per day, was continued and the patient was started on a regimen of 1-a-hydroxycholecalciferol (1-OH-D3) $3 \mu \mathrm{g}$ per day, calcium lactate $6 \mathrm{~g}$ per day and aluminum hydroxide suspension $120 \mathrm{ml}$ per day. Within eight days, serum calcium and phosphorus were 2.5 and $1.5 \mathrm{mmol} / \mathrm{l}$ respectively, and the Chvostek and Trousseau signs became negative. The same therepeutic regimen was continued and three weeks later the patient reported a marked decrease in the involuntary movements; by then, the serum calcium and phosphorus were 2.0 and 1.8 $\mathrm{mmol} / \mathrm{l}$ respectively. By the tenth week of treatment the movements completely disappeared, and the serum calcium and phosphorus were $2 \cdot 1$ and $1.6 \mathrm{mmol} / \mathrm{l}$ respectively.

\section{Discussion}

The clinical and biochemical data on this patient are consistent with long standing hypoparathyroidism which presumably had been inadequately controlled owing to poor patient compliance. Both the duration and severity of the hypoparathyroid state are believed to be factors favouring the development of cerebral calcification. ${ }^{7}$ The data on our patient support the recent findings of Forman et $\mathrm{al}^{7}$ and Brannan et $^{\mathrm{a}} \mathrm{l}^{8}$ of the superiority of CT scan over plain skull radiographs in detecting cerebral calcifications. Using CT, Forman et al found calcification in five out of nine patients with post-operative hypoparathyroidism and two out of two patients with idiopathic hypoparathyroidism. ${ }^{7}$ In the same group of 11 patients, cerebral calcifications were demonstrable in only one patient by plain skull radiographs.

Basal ganglia calcification can result from a variety of causes other than hypoparathyroidism, and the neurological sequelae are variable irrespective of the underlying cause. While some patients may be asymptomatic for years, ${ }^{8}$ the Mayo Clinic experience has revealed that extrapyramidal motor manifestations including chorea or athetosis occurred in about $25 \%$ of 38 patients. $^{2}$ Of interest is that the neurological abnormalities were partially or totally reversible only in those patients in whom the calcifications were due to hypoparathyroidism. ${ }^{2}$ The improvement, which may only be partial, usually follows correction of the hypocalcaemia with high doses of vitamin D and oral calcium supplements. ${ }^{2} 9$ In our patient, the swift correction of the hypocalcaemia was achieved with the use of the new synthetic vitamin D analogue, 1-OH-D3, which has the advantage of a more rapid onset of action than vitamin D or dihydrotachysterol. ${ }^{10} 11$

\section{References}

${ }^{1}$ Sugar O. Central neurological complications of hypoparathyroidism. Arch Neurol Psychiat 1953;70: 86-107.

2 Meunter MD, Whisnant JP. Basal ganglia calcification, hypoparathyroidism and extra pyramidal motor manifestations. Neurology (Minneap) 1968;18:107581.

${ }^{3}$ Schneider AB, Sherwood LM. Pathogenesis and management of hypoparathyroidism and other hypocalcemic disorders. Metabolism 1975;24:871-98.

${ }^{4}$ Bennet JC, Roy HM, Steinback HL. The significance of bilateral basal ganglia calcification. Radiology 1959;72:368-77.

${ }^{5}$ McKinney AS. Idiopathic hypoparathyroidism presenting as chorea. Neurology (Minneap) 1962;12: 485-91.

${ }^{6}$ Frame B. Parkinsonism in postoperative hypoparathyroidism. Arch Intern Med $1965 ; 116: 424-7$.

${ }^{7}$ Forman MB, Sandler MP, Danziger A, Kalk WJ. Basal ganglia calcification in post operative hypoparathyroidism. Clin Endocrinol 1980;12:385-90.

${ }^{8}$ Brannan TS, Burger AA, Chandhary MY. Bilateral basal ganglia calcifications visualized on CT scan. J Neurol Neurosurg Psychiatry 1980;43:403-6.

${ }^{9}$ Tabaee-Zadeh MJ, Frame B, Kapphahn K. Kinesiogenic choreoathetosis and idiopathic hypoparathyroidism. New Eng J Med 1972;286:762-3.

${ }^{10}$ Khalil AA, Salti IS. A safe dose schedule of one-alphahydroxycholecalciferol in hypoparathyroidism. Jordan Med J 1980;14:35-41.

11 Lewin IG, Papapoulos SE, O'riordan JLH. $1 a-$ hydroxy vitamin D3 in the long term management of hypoparathyroidism. Clin Endocrinol 1977; 7 Suppl:203S-207S. 